\title{
0 ensino de Ciências nas séries iniciais e a formação do professor nas instituições públicas paulistas
}

\author{
The science teaching in initial grades and the teacher \\ training in public colleges of São Paulo state
}

Daniel Fernando Bovolenta Ovigli

Monike Cristina Silva Bertucci

\begin{abstract}
Resumo
O ensino de Ciências nas séries iniciais possui algumas especificidades quando comparado àquele praticado em outras etapas da Educação Básica. Uma delas é o fato de contar com um professor polivalente, em geral graduado em Pedagogia e também responsável pelo ensino de outras áreas do conhecimento. Este trabalho teve como meta realizar um estudo acerca das características, fundamentos e concepções que norteiam a formação do pedagogo para o ensino de Ciências em cursos de Pedagogia oferecidos por instituições públicas localizadas no estado de São Paulo. O material de análise consistiu nas ementas e programas detalhados das disciplinas Metodologia de Ensino de Ciências (MEC) e afins. Verificou-se que os programas acentuam os aspectos metodológicos em detrimento dos conteúdos específicos de Ciências havendo, em alguns casos, dissociação da prática de ensino no contexto da disciplina MEC. Algumas recomendações incluem o aumento da carga horária da disciplina e sua vinculação com a prática de ensino.
\end{abstract}

Palavras-chave: ensino de Ciências; pedagogia; formação de professores.

\begin{abstract}
Science teaching in initial grades of elementary school has some special features when compared to that practiced in other stages of the process of schooling. One of them concerns the fact of having a multipurpose teacher, in general graduated in pedagogy and also responsible for teaching other areas of knowledge. This work had a goal study the characteristics and conceptions that guide the training of educator for teaching science in undergraduate courses offered by public institutions of higher education located in São Paulo state. The material of analysis consisted in menus and programs detailing the disciplines Methodology for Science Teaching (MEC). It was found that the programs emphasize methodological issues in detriment of specific contents of Natural Sciences, in some cases, decoupling the practice of teaching in the context of discipline MEC. Some recommendations include increasing the working hours of discipline and their link with the practice of teaching.
\end{abstract}

Keywords: science teaching; pedagogy; teacher training. 


\section{Introdução}

A importância do ensino de Ciências Naturais em todos os níveis de escolaridade tem sido muito discutida e diversos trabalhos defendidos em programas de pós-graduação brasileiros corroboram essa relevância no tocante às séries iniciais (Zanon, 2005; Ducatti-Silva, 2005; Silva, 2006). "A importância do ensino de ciências é reconhecida por pesquisadores da área em todo o mundo, havendo uma concordância relativa à inclusão de temas relacionados à Ciência e à Tecnologia nas séries iniciais" (Lorenzetti, 2005, p. 1). Embora haja convergência de opiniões quanto à necessidade do ensino de Ciências, já presente nos currículos e planejamentos escolares, ainda hoje a formação científica oferecida nas primeiras séries não é suficiente se considerarmos como um de seus principais objetivos a compreensão, pela criança, do mundo que a cerca (Lorenzetti, 2005).

"Para que um país esteja em condições de atender às necessidades fundamentais de sua população, o ensino de ciências e tecnologia é um imperativo estratégico [...]. Hoje, mais do que nunca, é necessário fomentar e difundir a alfabetização científica em todas as culturas e em todos os sectores da sociedade" (Declaração de Budapeste, 1999).

Nesse contexto, o ensino de Ciências deve proporcionar a todos(as) os(as) cidadãos(as) os conhecimentos e oportunidades de desenvolvimento de capacidades necessárias para se orientarem em uma sociedade complexa, compreendendo o que se passa à sua volta, tomando posição e intervindo em sua realidade (Chassot, 2003).

Segundo Fracalanza, Amaral e Gouveia (1986, p. 26 - 27):

"O ensino de ciências, entre outros aspectos, deve contribuir para o domínio das técnicas de leitura e escrita; permitir o aprendizado dos conceitos básicos das ciências naturais e da aplicação dos princípios aprendidos a situações práticas; possibilitar a compreensão das relações entre a ciência e a sociedade e dos mecanismos de produção e apropriação dos conhecimentos científicos e tecnológicos; garantir a transmissão e a sistematização dos saberes e da cultura regional e local".

As razões acima elencadas se contrapõem ao ensino centrado no livro didático, memorístico, acrítico e a-histórico praticado na maioria das escolas. Visando à mudança desta 
realidade, torna-se necessário desenvolver um ensino de Ciências que tenha como foco, logo nas séries iniciais do processo de escolarização, "a ação da criança, a sua participação ativa durante o processo de aquisição do conhecimento, a partir de desafiadoras atividades de aprendizagem" (Frizzo e Marin, 1989, p. 14).

Desta maneira, poderemos possibilitar condições para que o sujeito da aprendizagem exerça sua cidadania. "Para o exercício pleno da cidadania, um mínimo de formação básica em ciências deve ser desenvolvido, de modo a fornecer instrumentos que possibilitem uma melhor compreensão da sociedade em que vivemos" (Delizoicov e Angotti, 1990, p.56). Assim, todos os indivíduos devem receber uma formação mínima em ciências naturais para a sua formação cultural, uma vez que o conhecimento científico é parte constituinte da cultura construída pela humanidade. Além disso, é "no âmbito das séries iniciais que a criança constrói seus conceitos e apreende de modo mais significativo o ambiente que a rodeia, através da apropriação e compreensão dos significados apresentados mediante o ensino das Ciências Naturais" (Lorenzetti, 2005, p. 2).

As Ciências da Natureza, portanto, precisam ser entendidas como um elemento da cultura e também como uma construção humana, considerando que os conhecimentos científicos e tecnológicos desenvolvem-se em grande escala na atual sociedade. A prática pedagógica, portanto, deve possibilitar, para além da mera exposição de idéias, a discussão das causas dos fenômenos, o entendimento dos processos em estudo, a análise acerca de onde e como aquele conhecimento apresentado em sala de aula está presente nas vidas dos sujeitos e, sempre que possível, as implicações destes conhecimentos na sociedade.

\section{A formação do professor e o ensino de Ciências nas séries iniciais}

É fato que a formação dos professores constitui um fator de grande relevância do quadro de problemas percebidos no ensino de Ciências. Sabe-se que o professor termina o curso de Magistério e a licenciatura em Pedagogia, geralmente sem a formação adequada para ensinar Ciências Naturais (Ducatti-Silva, 2005).

Nesse sentido, o ensino de Ciências para as primeiras séries do Ensino Fundamental possui algumas peculiaridades quando comparada ao das séries subseqüentes. Sua principal característica é o fato de ser praticada por um professor polivalente, em geral responsável também pelo ensino de outras disciplinas. "Independente se este é um fator que facilita ou não o ensino de Ciências nesta etapa da escolaridade, o que pesquisas têm apontado é que ele apresenta um rol de problemas" (Longhini, 2008, p. 241).

Bonando (1994) diz que o ensino de Ciências da Natureza tem sido muito superficial e o professor, muitas vezes transcreve na lousa listas de exercícios para as crianças estudarem para as 
provas escritas, cabendo a elas decorar conceitos. Para esse mesmo autor, os docentes justificam que o reduzido número de atividades em Ciências neste nível de ensino (e que muitas vezes sequer existem) deve-se ao nível de escolaridade dos estudantes, que por estarem ainda em fase de alfabetização, nem sempre necessitam aprender sobre este componente curricular. No entanto, os próprios Parâmetros Curriculares Nacionais (Brasil, 1998) advogam a importância de se ensinar conteúdos deste componente curricular desde as primeiras séries da escolarização básica.

Em uma breve retrospectiva histórica acerca do ensino de Ciências para as séries iniciais Hamburger (2007) relata que no antigo Grupo Escolar as professoras (a grande maioria mulheres), eram formadas nas Escolas Normais. A formação em Ciências era bastante deficitária e, dessa forma, pouco ensinavam essa disciplina. Em 1961 foi aprovada a primeira Lei de Diretrizes e Bases da Educação Nacional (lei 4024/61) e algum tempo depois foram estabelecidos, pelo Conselho Federal de Educação, os "currículos mínimos" para as licenciaturas. Dez anos depois, com a promulgação da lei 5692/71, foi editada nova Lei de Diretrizes e Bases da Educação, e o tradicional Curso Normal, para formação docente para o então chamado Primário, foi substituída pela habilitação profissionalizante no Ensino Médio comum, resultando em desvalorização. Com a LDB aprovada em 1996 (9394/96), passa a haver a exigência de formação em nível superior para atuação docente em toda a Educação Básica, desde a Educação Infantil até o Ensino Médio.

"Entretanto, em vez do Curso Normal superior previsto na lei, foi adaptado o antigo curso de Pedagogia, que se destinava a formar técnicos universitários em administração escolar mais do que professores. O resultado é que não há, atualmente, estrutura legal nem curso adequados para uma boa formação dos professores das séries iniciais, talvez os mais importantes na educação das crianças! Para o ensino de Ciências, a situação não parece ter melhorado com a exigência de nivel superior; os futuros professores continuam aprendendo muito pouca ciência e têm dificuldade de tratar temas científicos em aula" (Hamburger, 2007, p. 96).

Em 2007, com a publicação de um novo relatório sobre o ensino de Ciências nas séries iniciais (Duschl et al, 2007, apud Hamburger, 2007) da National Academy of Sciences/National Research Council dos Estados Unidos, fica evidente a relevância do resultado de pesquisas educacionais realizadas com crianças a partir de 5-6 anos: ao ingressarem na escola, já têm capacidade intelectual para aprender Ciências Naturais e, inclusive, fazer experimentação. "O desafio do educador é despertar a curiosidade e essa capacidade. O desafio maior é formar o educador e prover condições para que atue com sucesso" (Hamburger, 2007, p. 101). 
No caso específico dos discentes do curso de Pedagogia, que praticamente não têm disciplinas de conteúdo de Ciências Naturais, deve ser propiciado um ambiente no qual sintam necessidade de aprender, questionando e contestando não somente suas concepções (Villani e Freitas, 1998), mas também seus valores e convicções pessoais e, dessa forma, sintam vontade e satisfação em aprender, em explorar e testar seus pensamentos, idéias e perspectivas.

A esse respeito convém citar as Diretrizes Curriculares Nacionais Para Formação de Professores da Educação Básica em Nível Superior, Curso de Licenciatura, de Graduação Plena (Brasil, 2001). Em seu artigo 50 este documento explicita que o projeto político-pedagógico de cada Curso deve considerar uma formação que propicie a construção de competências necessárias à atuação do egresso na Educação Básica, incluindo uma seleção de conceitos além daqueles que os licenciandos irão ensinar futuramente, bem como a articulação desses conceitos com suas didáticas específicas.

\begin{abstract}
"No entanto, não seria descabido afirmar que a formação de professores no Brasil dificilmente figura entre as prioridades do sistema universitário, especialmente quando nos referimos ao sistema público. Os professores polivalentes que atuam nas quatro primeiras séries do ensino fundamental têm poucas oportunidades de se aprofundar no conhecimento científico e na metodologia de ensino específica da área, tanto quando sua formação ocorre em cursos de magistério como em cursos de Pedagogia" (Bizzo, 2002, p. 65).
\end{abstract}

Além da discussão fundamentada nas ementas/programas detalhados das disciplinas de Metodologia de Ensino de Ciências e afins, pesquisadas nas cinco instituições formadoras consideradas para realização deste trabalho, fez-se necessário contemplar o decreto no. 3.276/99, que dispõe sobre a formação docente para atuação na Educação Básica. Seu artigo 2 o explicita que os cursos deverão possibilitar uma "formação básica comum, com concepção curricular integrada, de modo a assegurar as especificidades do trabalho do professor na formação para atuação multidisciplinar e em campos específicos do conhecimento" (Brasil, 1999), coerente com os documentos oficiais que regulamentam o ensino de uma área multidisciplinar como as Ciências Naturais, em particular aquela tratada nas primeiras séries do processo de escolarização (Brasil, 1998).

"Assim, o profissional deverá estar preparado para atuar na Educação Infantil e nas
séries iniciais do Ensino Fundamental, na administração e no trabalho de assessoria 
às escolas, como também terá uma formação que lhe permitirá exercer o magistério de modo crítico, criativo e comprometido com a educação das crianças" (DucattiSilva, 2005, p. 114).

Gadotti (1998) sinaliza para algumas respostas no que tange à atual prática do professor(a). Para ele o curso de Pedagogia, fragmentado como é, acarreta o problema existente nas Práticas de Ensino e, dessa forma, o licenciando não tem um estudo aprofundado em Ciências Naturais. Nesse contexto, o presente trabalho objetivou analisar como se processa a formação do pedagogo nos cursos oferecidos pelo sistema público paulista de ensino superior, por julgarmos ser este o lócus preferencial para a formação de profissionais para atuação nas séries iniciais da Educação Básica.

\section{Materiais e Método}

Nesse contexto, o presente trabalho objetivou o levantamento das características, dos fundamentos e dos pressupostos/concepções que norteiam a formação do pedagogo para o ensino de Ciências para as séries iniciais. Os cursos de graduação em Pedagogia investigados são oferecidos pelo sistema público paulista de ensino superior, estadual e federal. Para alcançar esse objetivo, realizou-se uma busca nas páginas on line das instituições de ensino superior em questão, tentando caracterizar os cursos, bem como o enfoque dado ao ensino de ciências naturais nos currículos de graduação. Além da consulta aos sites das instituições, o levantamento foi realizado com base nas ementas/programas detalhados das disciplinas de "Metodologia de Ensino de Ciências Naturais" e afins. Quando a ementa ou programa não estava disponibilizado diretamente no site da Instituição de Ensino Superior (IES), um e-mail foi encaminhado à Seção de Graduação da respectiva instituição, explicitando-se os objetivos deste trabalho visando à obtenção do programa/ementa.

\section{Resultados e Discussão}

\section{Um panorama dos cursos de Pedagogia oferecidos no estado de São Paulo}

A dispersão dos cursos de Pedagogia no estado de São Paulo é bastante evidente, havendo oferecimento desse curso em praticamente todas as regiões do estado. Três instituições 
pertencem ao sistema público estadual de ensino ${ }^{1}$ e duas instituições são federais ${ }^{2}$. Para a identificação das instituições serão utilizadas as letras $E$, em se tratando de IES estadual e $F$, caso o curso em questão seja oferecido por uma universidade federal. Como algumas instituições apresentam vários cursos de Pedagogia em diferentes campi, suas grades curriculares podem ser diferentes. Nesse caso, visando à distinção dos cursos ofertados em diferentes unidades da instituição, a letra $C$ acompanhada de um respectivo número designará a cidade na qual o curso é ofertado. Assim, E1C3 denota a instituição estadual 1 cujo curso de Pedagogia é ministrado na cidade 3.

Tabela 1: os cursos de Pedagogia oferecidos por IES públicas

\begin{tabular}{cccc} 
& Estadual & Federal & Total \\
\hline Instituições & 3 & 2 & 5 \\
Cursos & 14 & 4 & 18
\end{tabular}

Da tabela 1, verifica-se que as instituições estaduais oferecem $77,7 \%$ do total do total de cursos de Pedagogia ofertados pelo sistema público de ensino superior do estado de São Paulo. Tomando por base o vestibular 2009 foram oferecidas 875 vagas em cursos presenciais, selecionados como amostra para esta investigação.

Destaca-se o fato de que algumas instituições oferecem turmas em dois períodos. Todas as instituições pesquisadas oferecem vagas no período noturno, algumas exclusivamente nesse período, outras juntamente com o período matutino ou vespertino, conforme listado na tabela 2 . Quando o campus em análise oferece o curso de Pedagogia em dois turnos, a grade curricular é a mesma para ambos os períodos: o fluxo curricular de E2C1, por exemplo, é o mesmo tanto para o período matutino quanto para o noturno. Assim, embora existam 18 cursos de Pedagogia

1 São elas: Universidade de São Paulo (USP), campi São Paulo e Ribeirão Preto; Universidade Estadual Paulista "Júlio de Mesquita Filho" (Unesp), campi Bauru, Araraquara, Presidente Prudente, Rio Claro, São José do Rio Preto e Marília e Universidade Estadual de Campinas (UNICAMP).

2 As instituições de ensino superior vinculadas ao governo federal compreendem a Universidade Federal de São Carlos (UFSCar) e Universidade Federal de São Paulo (UNIFESP), campus Guarulhos. 
oferecidos por instituições públicas no estado de São Paulo, as grades curriculares analisadas totalizam 11.

Tabela 2: período no qual o curso é oferecido

\begin{tabular}{cccc} 
Instituição & Matutino & Vespertino & Noturno \\
\hline E1C1 & $X$ & $X$ \\
E1C2 & $X$ & $X$ \\
E2C1 & $X$ & $X$ \\
E2C2 & & $X$ \\
E2C3 & & $X$ \\
E2C4 & & $X$ & $X$ \\
E2C5 & & $X$ \\
E2C6 & & $X$ \\
E3C1 & $X$ & $X$ \\
F1C1 & $X$ & $X$ \\
F2C1 & & $X$ & $X$
\end{tabular}

Em um levantamento que levou em consideração o número de vagas oferecidas nos últimos anos nota-se um aumento significativo, particularmente quanto às vagas ofertadas no período noturno, uma possível influência das políticas governamentais de incentivo à docência, bem como a recente aprovação do REUNI (Programa de Apoio ao Plano de Reestruturação e Expansão das Universidades Federais).

O número de créditos destinados à disciplina em análise em cada uma das instituições pesquisadas segue na Tabela 3 ( 1 crédito equivale a 15 horas de aula):

Tabela 3: número de créditos por instituição pesquisada

\begin{tabular}{cccccccccccc} 
Instituição & E1C1 & E1C2 & E2C1 & E2C2 & E2C3 & E2C4 & E2C5 & E2C6 & E3C1 & F1C1 & F2C1 \\
\hline Créditos & 4 & 4 & 8 & 8 & 5 & 6 & 5 & 8 & 6 & 6 & $\begin{array}{c}10 \\
\text { (anual) }\end{array}$
\end{tabular}




\section{A ocorrência da formação científica}

\section{frente ao panorama apresentado}

Para conseguirmos as indicações da formação em ciências naturais para o pedagogo, tivemos como referência os títulos das disciplinas e ementas, pois ao pesquisar essas indicações nos currículos, nos deparamos com as seguintes distinções na disponibilização: instituições que disponibilizam somente a grade curricular e instituições que disponibilizam, além do fluxo curricular, as ementas/programas detalhados das disciplinas oferecidas ao longo de todo o curso. Acessamos a todas essas modalidades curriculares disponibilizadas, sendo que nelas foi possível verificar qual o espaço dado pelos cursos às disciplinas voltadas ao ensino de Ciências Naturais. Fundamentalmente três categorias puderam ser levantadas a partir da busca realizada: disciplinas focadas unicamente na metodologia de ensino, outras que contemplam metodologia e prática de ensino e disciplinas ancoradas na abordagem conhecimento específico/metodologia de ensino (incluindo, por vezes, a prática como componente curricular), esta última com menor freqüência. De modo geral, o oferecimento da disciplina encontra-se concentrado a partir da segunda metade do curso (que pode ter duração de quatro ou cinco anos) ou seja, a partir do 5o semestre, podendo ser oferecida até o oitavo. E2C5 é a única instituição que oferece a disciplina logo no primeiro ano do curso. Verificou-se também que quando o curso apresenta a disciplina oferecida em dois semestres, há um primeiro momento, que aborda a parte específica de conceitos voltados às ciências naturais; em um segundo momento trata-se da respectiva metodologia de ensino. Ressaltamos que os apontamentos aqui traçados levarão em consideração os objetivos gerais e específicos da disciplina Metodologia de Ensino de Ciências e afins bem os conceitos nela estudados em cada uma das instituições pesquisadas.

\section{Alguns apontamentos}

Quanto à nomenclatura utilizada para designar a disciplina, há variações, mesmo quando se considera diferentes campi de uma mesma IES. "Conteúdos, Metodologias e Prática de Ensino de Ciências Naturais" (E2C1, E2C3, E2C6, F2C1), "Metodologia e Prática de Ensino de Ciências" (F1C1), "Conteúdos e Metodologia do Ensino de Ciências" (E2C2, E2C5) e "Metodologia do Ensino de Ciências" (E1C1, E1C2, E2C4, E3C1).

O objetivo geral presente na ementa do curso E1C1 sintetiza as metas presentes nos demais currículos: "Subsidiar e preparar os alunos para o planejamento e a programação de curso de ciências e propiciar-lhes a vivência e a reflexão da prática docente". A vivência a que se refere o excerto relaciona-se à carga horária de prática de ensino de ciências naturais, já incluída na 
carga horária prevista para a integralização da disciplina, presente em cinco das onze ementas analisadas.

A totalidade das ementas/programas analisados coloca em evidência a necessidade do ensino de ciências nas séries iniciais e as propostas que orientam seu ensino, a exemplo da ementa de F1C1: "Conhecer e discutir as propostas curriculares, algumas pesquisas e projetos, visando o ensino de ciências naturais nas séries iniciais e sua função. Compreender o significado das Ciências e sua importância na formação dos alunos desde as séries iniciais". A IES E2C6 assim explicita seus objetivos: "Conhecer e articular os fundamentos básicos das áreas de conhecimento que integram a disciplina para compreender a dinâmica da realidade e superar a visão compartimentalizada e reducionista de ambiente e, a partir deste estudo, analisar criticamente a disciplina Ciências Naturais no Ensino Fundamental".

Fumagali citado por Weissmann (2004) discorre sobre a necessidade do ensino de ciências na escola básica, traduzido pelo direito que as crianças têm de aprender ciências. Para a autora, crianças são integrantes do corpo social e tem o mesmo direito dos adultos de apropriar-se da cultura elaborada (da qual faz parte o conhecimento científico) para utilizá-la na explicação e transformação do mundo que as cerca. Também trata a escola como a instituição social encarregada de distribuir à população um conjunto de conteúdos culturais que nem os grupos primários como a família, os meios de comunicação social ou o desenvolvimento espontâneo da criança na vida coletiva são capazes de transmitir ou gerar.

Coerente com tais pressupostos, o programa detalhado da disciplina E2C3 sinaliza para "uma análise crítica da Ciência", bem como "a reflexão e análise a partir do concreto, do próprio meio que cerca a criança e a atividade do homem sobre a natureza". Trata-se de uma abordagem também preconizada por F1C1, ao reconhecer como um dos objetivos da disciplina o conhecimento e análise crítica de pesquisas e projetos, visando ao ensino de Ciências nas séries iniciais do ensino fundamental regular e EJA.

Da mesma forma F2C1, destaca em sua ementa "O ensino de ciências nas séries iniciais. Proposta metodológica construtivista para o ensino de ciências nas séries iniciais", assim como em E2C1: "alguns caminhos para o "fazer ciência" na sala de aula: idéias prévias versus conhecimento científico, história da ciência, cotidiano, tecnologias, experimentação", mostrando a força que os debates acerca do construtivismo ainda têm na educação em ciências (Bizzo, ElHani, 2002).

Em consonância com os propósitos da discussão aqui apresentada, Bizzo (2005) ressalta que o ensino de ciências é alvo de debates há pelo menos 30 anos. Nesse sentido, tem ganhado crescente importância, nos últimos anos, a relação da Metodologia de Ensino de Ciências com as 
concepções que os sujeitos da aprendizagem têm acerca dos conceitos da área de ciências naturais. Para Ducatti-Silva (2005, p. 101)

\begin{abstract}
“(...) esses conceitos são construídos a todo o momento, mas há de se fazer um contato mais bem sistematizado entre aquilo que é oferecido no currículo do Curso de Pedagogia e aquilo que é oferecido no ensino das crianças, para posterior modificação na organização de como é tratado o ensino de Ciências em nível de formação".
\end{abstract}

Em apenas duas das instituições pesquisadas (E2C6 e F2C1) a disciplina é oferecida em dois semestres e difere das outras propostas considerando os dois momentos que apresenta. Em E2C6 o primeiro momento é dedicado ao estudo conteúdos científicos específicos e, posteriormente, no tópico intitulado "Articulando Idéias", conforme consta na ementa, se objetiva a apresentação dos "fundamentos teóricos e metodológicos de interdisciplinaridade e metodologia do ensino de Ciências Naturais para as séries iniciais do Ensino Fundamental". E2C6 é também a única instituição na qual a disciplina é oferecida por um departamento de Educação em co-responsabilidade com departamentos de Biologia, Química e Física. Já F2C1 expressa em sua ementa

\begin{abstract}
"Fundamentos de Física: movimento dos corpos, óptica, termologia acústica, eletromagnetismo. Fundamentos de Química: substâncias, mudanças de estado físico, teoria atômico-molecular, combustão e combustível, conservação de alimentos, processos industriais. Ciências da Vida: animais, vegetais, nutrição $e$ saúde, educação ambiental. Fundamentos de geociências. A Terra e seus ambientes".
\end{abstract}

De modo geral, os temas propostos pelas ementas são bastante variados, mas sempre giram em torno dos seguintes assuntos:

- Ensino Ciências: panorama das abordagens teóricas e pesquisas da área.

- Referenciais curriculares nacionais e regionais para o ensino de ciências na educação infantil e ensino fundamental.

- Os conteúdos no Ensino de Ciências.

- Planejamento de atividades e definição de objetivos.

- Atividades Práticas e Experimentação. 
- Recursos Didáticos no Ensino de Ciências: livros didáticos, materiais audiovisuais e computadores.

- Avaliação no Ensino de Ciências

Considerando que a partir dos anos 80 há uma mudança de paradigma, reforçando a percepção de Ciência como construção humana e não como "verdade natural", novas abordagens de ensino destacam a importância da História da Ciência no processo educacional preconizada, inclusive, pelos Parâmetros Curriculares Nacionais (PCNs). Nesse sentido, chama a atenção a inclusão da História da Ciência na ementa do curso oferecido por F2C1, "A História da Ciência como eixo disciplinar". Ressalta-se que tanto a História da Ciência como a experimentação, muito difundida na década de 1970, é foco de poucos trabalhos publicados na área, conforme apontado por Araújo e Abib (2003). Quanto à experimentação no ensino de ciências convém citar, mais uma vez, Ducatti-Silva $(2005$, p. 179)

"[a experimentação] gera grandes expectativas nos graduandos. Isso ocorre porque a prática fornece um caminho certo para os experimentos, auxiliando os graduandos que exercem a profissão, no momento de trabalhar os conteúdos indicados pelos livros didáticos. Há nessa prática a reprodução daquilo que se aprendeu, o que fortalece a idéia da falta de tradição de pesquisa no ensino de Ciências. Partilham dessa mesma visão, sobre o conceito de Ciência que é estereotipado pelo espaço de laboratório, uma boa parte da sociedade".

Como perspectiva utilizada mais recentemente no ensino de ciências naturais que visa à aproximação deste campo com a sociedade, entra em cena a perspectiva Ciência-TecnologiaSociedade-Ambiente (CTSA) e discussões que envolvem a alfabetização científica nas séries iniciais. Trata-se de uma discussão contemplada nas ementas de F1C1 ao citar a "visão comparativa entre a ciência, o senso comum e as crendices populares" e também ao contemplar a "apresentação e discussão da abordagem Ciência-Tecnologia-Sociedade-Ambiente", abordagem também citada por E2C1. A esse respeito E3C1 congrega a "concepção de Ciência, Ambiente, Tecnologia e Sociedade e suas relações, subjacentes aos principais modelos curriculares de ensino de Ciências", articulando currículo e relações CTSA. "Reconhecer seu papel [do educando] na sociedade contemporânea, particularmente na relação Ciência, Tecnologia, Sociedade e Ambiente". (F1C1) 


\begin{abstract}
"Assim, espera-se que as questões públicas envolvendo a ciência sejam melhores compreendidas e que melhores decisões sejam tomadas quanto maior for $o$ entendimento público da ciência. Melhorar o entendimento público de ciência e influenciar na tomada de decisões, nos órgãos governamentais e na vida prática das pessoas, constituem-se em metas para as quais o ensino de Ciências Naturais certamente poderá contribuir. Através desta disciplina, nas Séries Iniciais do Ensino Fundamental, certamente a alfabetização científica poderá contribuir para que o aluno realize uma leitura inicial de mundo, compreendendo os significados dos conteúdos da ciência e de seus processos de produção" (Lorenzetti, 2005, p. 6-7).
\end{abstract}

A epistemologia na formação do professor para as séries iniciais é bastante evidente na ementa apresentada pela IES E1C1 como objetivos de formação do pedagogo: "caracterizar o conhecimento científico, diferenciando-o de outras formas do conhecimento e identificar as áreas das Ciências Naturais - Biologia, Química, Física e Geologia e seus diferentes objetos de estudo sua natureza e estrutura, bem como o(s) método(s) científico(s) e os métodos de ensino de ciências".

No tocante aos conceitos científicos, quando existem, caso de $\mathrm{E} 2 \mathrm{C} 6$ e $\mathrm{F} 2 \mathrm{C} 1$, por terem curta duração, podem não garantir formação completa do ensino em questão; é preciso uma formação básica dos assuntos e, por isso, há necessidade da formação para a pesquisa estabelecendo a integração de outras áreas, como o caso da Prática de Ensino, que precisa ser articulada à disciplina de Metodologia de Ensino de Ciências, como ocorre em algumas instituições. Por vezes, trata-se de uma prática que não acontece por falta de articulação entre os próprios professores universitários (Ducatti-Silva, 2005). Além disso, verificou-se que as disciplinas intituladas "Conteúdos, Metodologia e Prática de Ensino de Ciências" supervalorizam a metodologia em detrimento dos conteúdos, que aparecem nas ementas por vezes confundidos com o estudo dos currículos de ciências das séries iniciais, estudos que não abarcam os conceitos científicos propriamente, caso de E2C1 e E2C3.

Finalmente, pode-se dizer que as propostas curriculares assumidas por estas instituições se caracterizam por múltiplas diferenciações que nos permitem constatar o caráter híbrido que norteia o desenvolvimento da disciplina em cada instituição pesquisada.

\title{
Considerações Finais
}

Enquanto cidadãos e cidadãs pertencentes a uma sociedade democrática, todos(as) somos convidados(as) a discutir e opinar em assuntos que envolvem a Ciência e a Tecnologia. 
Também no dia-a-dia e no trabalho as pessoas estão envolvidas de diferentes formas com questões que envolvem conhecimentos da área de Ciências da Natureza. Desse modo, as pessoas necessitam de algum entendimento científico, para auxiliá-las quer diariamente em sua vida pessoal e profissional, quer em decisões no âmbito das relações sociais. (Gil e Vilches, 2006).

Para que essa aprendizagem ocorra é necessário que as atividades docentes privilegiem a atribuição de significados e a compreensão dos conteúdos ensinados na escola em oposição ao ensino memorístico, descontextualizado e a-histórico encontrado, ainda hoje, nas escolas. (Lorenzetti, 2005).

Segundo as ementas e programas analisados das instituições pesquisadas, podemos afirmar que existe preocupação em formar um profissional bem preparado para atuar na educação. A aquisição da capacidade de entender os parâmetros das Ciências Naturais como atividade humana, como prática de produção e criação, compreendendo a dinâmica da realidade norteia o perfil do profissional a ser formado por todas as IES investigadas e também evidenciam a necessidade de integração de diferentes áreas do conhecimento para resolver situaçõesproblema. Constatamos ainda, que algumas IES visam à articulação teoria-prática no trabalho pedagógico, tendo parâmetros que orientem a tomada de decisões e a organização de conceitos a serem trabalhados futuramente pelos licenciandos em sua prática pedagógica por meio da aproximação do licenciando, ainda durante a disciplina Metodologia de Ensino de Ciências, da escola fundamental, expresso por suas ementas que incluem a prática como componente da disciplina.

Segundo as Diretrizes Curriculares para formação de professores, o pedagogo é um profissional habilitado para atuar no ensino, na produção e difusão do conhecimento nas diversas áreas da educação e também na organização e gestão de instituições escolares, sendo a docência a base de sua identidade profissional. Entre estas, o profissional formado em Pedagogia também pode atuar na Educação de Jovens e Adultos (EJA) e educação para pessoas com necessidades especiais.

Mesmo com essa perspectiva, o aprofundamento teórico-metodológico na disciplina Metodologia de Ensino de Ciências sobre cada segmento de atuação do profissional formado fazse de modo bastante superficial segundo as ementas analisadas. Nesse sentido, não se garante a preparação para atuação desse profissional tendo em vista as necessidades dessa formação e o seu não atendimento (Ducatti-Silva, 2005).

O pensamento chama realmente a atenção porque, como já mencionado acima, ainda não se tem muito definido no curso de Pedagogia a formação do professor para o ensino de 
Ciências nas séries iniciais. Assim, julgamos importante o aumento do número de horas dedicadas à disciplina, bem como a vinculação da mesma à prática como componente curricular.

Nessa linha, partilhamos da idéia de que é indispensável se fazer o estudo de teorias que tenham nascido de uma prática real; pois, dessa maneira, tem-se maior clareza e consciência daquilo que é aplicado, seja na escola básica ou fora dela, na universidade.

A ressignificação da relação teoria e prática é muito debatida entre alunos e professores e ganha cada vez mais espaços em suas discussões e pensamentos cotidianos. Segundo Martins (1999), os saberes docentes transportam o significado do "o quê" e do "como" realizar as atividades relativas ao contexto da sala de aula, que, muitas vezes, estão desconexas dos cursos de formação de professores.

No contexto atual, o ensino de Ciências deve favorecer, além da construção de conteúdo conceitual (conceitos, fatos), o desenvolvimento no aluno de atitudes científicas, habilidades e competências, que só podem ser conseguidas através de uma orientação adequada e consciente. Além disso, o ensino de Ciências deve fazer sentido para o aluno e ajudá-lo a não apenas compreender o mundo físico, mas a reconhecer seu papel como participante em decisões individuais e coletivas. Para isso, é necessário que os professores reconheçam que em suas salas de aula, além de trabalharem definições, conceitos, também estão ensinando procedimentos, atitudes e valores e, nesse sentido, o comprometimento das IES com uma formação inicial de qualidade é peça-chave desse processo.

\section{Referências}

ARAÚJO, M.S.T.; ABIB, M.L.V.S. Atividades experimentais no ensino de Física: diferentes enfoques, diferentes finalidades. Revista Brasileira de Ensino de Física, v. 25, n. 2, p. 176-194, jun. 2003.

BIZZO, N.M.V. [s.d.]. Metodologia e prática de ensino de ciências: a aproximação do estudante de magistério das aulas de ciências no 1. grau. [S.I.]. Disponível em: <http://www.ufpa.br/eduquim/praticadeensino.htm>. Acesso em: 10 nov. 2008.

BIZZO, N.M.V. Ciências: fácil ou difícil? São Paulo: Ática, 2002.

BONANDO, P.A. Ensino de Ciências nas séries iniciais do 10 grau - descrição e análise de um programa de ensino e assessoria ao professor. 1994. Dissertação (Mestrado em Educação) Centro de Educação e Ciências Humanas, Universidade Federal de São Carlos, São Carlos, 1994.

BRASIL. Secretaria de Educação Fundamental. Parâmetros Curriculares Nacionais: Ciências Naturais. Brasília: Secretaria de Educação Fundamental, 1998. 
BRASIL. Ministério da Educação. Parecer no. CNE/CP 009/2000, de 8 de maio de 2001. Diretrizes Curriculares Nacionais para Formação de Professores da Educação Básica, em nível superior, curso de licenciatura, de graduação plena. Conselho Nacional de Educação, Brasília, DF, 8 mai. 2001. Disponível em: <http://www.mec.gov.br/cne/pdf/basica>. Acesso em: 30 nov. 2008.

BRASIL. Ministério da Educação. Decreto no. 3.276/99, de 6 de dezembro de 1999. Dispõe sobre a formação em nível superior de professores para atuar na educação básica, e dá outras providências. Conselho Nacional de Educação, Brasília, DF, 6 dez. 1999. Disponível em: <http://portal.mec.gov.br/cne/arquivos/doc/decr3276_99.doc>. Acesso em: 15 dez. 2008.

CHASSOT, A. Alfabetização científica: uma possibilidade para a inclusão social. Revista Brasileira de Educação, n. 22, p. 89 - 100, jan./fev./mar./abr.2003. Disponível em: <http://www.scielo.br/pdf/rbedu/n22/n22a09.pdf>. Acesso em: 12 nov. 2008.

Declaração de Budapeste. Marco geral de ação, 1999. Disponível em: <http://www.unesco.org/science/wcs/esp/declaracion_s.htm>. Acesso em: 15 nov. 2008.

DELIZOICOV, D.; ANGOTTI, A. Metodologia do Ensino de Ciências. São Paulo: Cortez, 1990.

DUCATTI-SILVA, K.C. A formação no curso de Pedagogia para o ensino de ciências nas séries iniciais. 2005. Dissertação (Mestrado em Educação) - Faculdade de Filosofia e Ciências, Universidade Estadual Paulista "Júlio de Mesquita Filho", Marília, 2005.

EL-HANI, C.N.; BIZZO, N.M.V. Formas de construtivismo: mudança conceitual e construtivismo contextual. Ensaio: Pesquisa em Educação em Ciências, v. 4, n. 1, jul. 2002. Disponível em: $<w w w . f a e . u f m g . b r / e n s a i o / v 4 \_n 1 / 4113 . p d f>$. Acesso em: 10 out. 2008.

FRACALANZA, H.; AMARAL, I.A.; GOUVEIA, M.S.F. O ensino de ciências no primeiro grau. São Paulo: Atual, 1986.

FRIZZO, M. N.; MARIN, E. B. O ensino de ciências nas séries iniciais. Ijuí: Editora UNIJUÍ, 1989.

GADOTTI, M. Pedagogia da práxis. São Paulo: Cortez, 1998.

HAMBURGER, E. W. Alguns apontamentos sobre o ensino de Ciências nas séries escolares iniciais. Estudos Avançados, v. 21, n. 60, p. 93 - 104, 2007. Disponível em: $<$ http://www.scielo.br/scielo.php?script=sci_arttext\&pid=S0103-

$40142007000200007 \&$ Ing=pt\&nrm=iso\&tlng=en>. Acesso em: 12 nov. 2008.

LORENZETTI, L.. O ensino de ciências naturais nas séries iniciais, 2005. Retirado em Disponível em:

$<$ www.faculdadefortium.com.br/ana_karina/material/O\%20Ensino\%20De\%20Ciencias\%20Naturai s\%20Nas\%20Series\%20Iniciais.doc>. Acesso em: 16 nov.2008. 
MARTINS, M.A.V. O teórico e o prático na formação de professores. Em: CAPPELLETTI, I. F.; LIMA, L.A.N. (Orgs.). Formação de educadores: pesquisas e estudos qualitativos. São Paulo: Olho d'água, 1999, p. 7- 18.

SILVA, A.F.A. Ensino e aprendizagem de Ciências nas séries iniciais: concepções de um grupo de professoras em formação. 2006. Dissertação (Mestrado em Ensino de Ciências), Faculdade de Educação, Universidade de São Paulo, São Paulo, 2006.

VILLANI, A.; FREITAS, D. Análise de uma experiência didática na formação de professores de

Ciências. Investigações em Ensino de Ciências, v. 3, n. 2, p. 121-142, 1998. Disponível em:

<http://www.if.ufrgs.br/ienci/artigos/Artigo_ID41/v3_n2_a1998.pdf>. Acesso em: 03 nov. 2008.

ZANON, D.A.V. Ensinar e aprender Ciências no ensino fundamental com atividades investigativas: enfoque no projeto $A B C$ na Educação Científica Mão na Massa. 2005. Tese (Doutorado em Educação) - Centro de Educação e Ciências Humanas, Universidade Federal de São Carlos, São Carlos, 2005.

GIL, D; VILCHES, A. Educación ciudadana y alfabetización científica: mitos y realidades. Revista Iberoamericana de Educación, n. 42, p. 31-53, 2006. Disponível em: <http://www.rieoei.org/rie42a02.htm>. Acesso em: 07 dez. 2008.

WEISSMANN, H. (Org.). Didática das Ciências Naturais: contribuições e reflexões. Porto Alegre: Artmed, 1998.

Daniel Fernando Bovolenta Ovigli: mestrando em Educação pela Universidade Federal de São Carlos (PPGE/UFSCar) junto à linha de pesquisa "Ensino de Ciências e Matemática" e professor efetivo junto à Prefeitura Municipal de Botucatu/SP. danielovigli@yahoo.com.br

Monike Cristina Silva Bertucci: mestranda em Educação pela Universidade Federal de São Carlos (PPGE/UFSCar) junto à linha de pesquisa "Ensino de Ciências e Matemática". Bolsista FAPESP (Processo 2008/02090-9). E-mail: mobertucci@yahoo.com.br. 